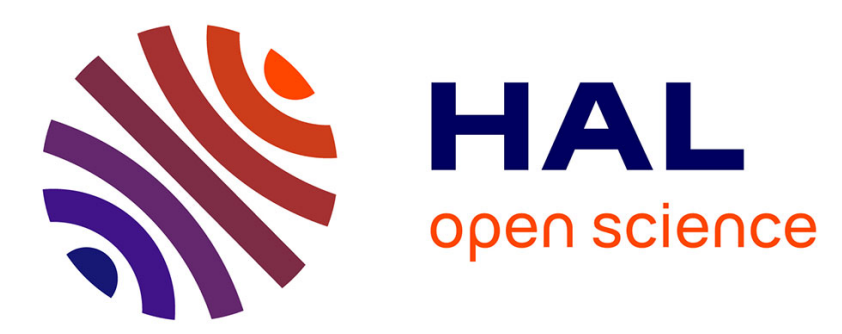

\title{
Wave-driven sea level anomalies at the Midway tide gauge as an index of North Pacific storminess over the past 60 years
}

Jérôme Aucan, R. Hoeke, M.A. Merrifield

\section{- To cite this version:}

Jérôme Aucan, R. Hoeke, M.A. Merrifield. Wave-driven sea level anomalies at the Midway tide gauge as an index of North Pacific storminess over the past 60 years. Geophysical Research Letters, 2012, 39 (17), pp.L17603. 10.1029/2012GL052993 . hal-00798722

\section{HAL Id: hal-00798722 \\ https://hal.science/hal-00798722}

Submitted on 8 Apr 2021

HAL is a multi-disciplinary open access archive for the deposit and dissemination of scientific research documents, whether they are published or not. The documents may come from teaching and research institutions in France or abroad, or from public or private research centers.
L'archive ouverte pluridisciplinaire HAL, est destinée au dépôt et à la diffusion de documents scientifiques de niveau recherche, publiés ou non, émanant des établissements d'enseignement et de recherche français ou étrangers, des laboratoires publics ou privés. 


\title{
Wave-driven sea level anomalies at the Midway tide gauge as an index of North Pacific storminess over the past 60 years
}

\author{
J. Aucan, ${ }^{1}$ R. Hoeke, ${ }^{2}$ and M. A. Merrifield ${ }^{3}$ \\ Received 6 July 2012; revised 25 July 2012; accepted 27 July 2012; published 5 September 2012.
}

[1] Sixty years of sea-level data collected in the interior lagoon of Midway Atoll in the northern Hawaiian Islands are used to examine short-term $(<2$ days), high amplitude (up to $1 \mathrm{~m}$ ) sea level anomaly (SLA) events that occur during the winter months. A combination of wind and wave model hindcasts, satellite altimetry product and in-situ water level data confirms that these high SLA events are driven primarily by the arrival of energetic swell waves generated by storms in the North Pacific as breaking waves on the northwest side of the atoll lead to the setup of the lagoon. The number of high SLA events recorded in Midway during each winter season correlates well with the storminess in the Central North Pacific, defined as the mean seasonal wave height. This leads us to conclude that the seasonal number of high SLA events measured at this specific tide gauge in Midway can be used as an index of storminess in the Central North Pacific over climatic time-scales. Our Midway-based index of storminess correlates well with the Pacific Decadal Oscillation (PDO) index, and its observed increase over the past 60 years is attributed to variability associated with the PDO rather than a long-term trend. Citation: Aucan, J., R. Hoeke, and M. A. Merrifield (2012), Wave-driven sea level anomalies at the Midway tide gauge as an index of North Pacific storminess over the past 60 years, Geophys. Res. Lett., 39, L17603, doi:10.1029/2012GL052993.

\section{Introduction}

[2] The oceanic coral atolls of the Pacific and Indian Oceans are exposed to high surface gravity wave energy. As this wave energy dissipates over their encircling reefs, the associated radiation stress gradient locally raises water levels and forces flow over the reef and into the lagoon [LonguetHiggins and Stewart, 1964; Symonds et al., 1995]. This inward flux of water is then compensated by an outward flow in channels cutting across the reef. This process has been identified as the primary flushing mechanism for atolls [Munk and Sargent, 1948; Tait, 1972], and the degree to which it occurs is an important determinant of lagoon water quality [Andrefouet et al., 2001; Callaghan et al., 2006]. This process can also cause a temporary increase in sea level and associated flooding of the entire lagoon in some cases

\footnotetext{
${ }^{1}$ LEGOS, IRD, Toulouse, France.

${ }^{2}$ CSIRO, Aspendale, Victoria, Australia.

${ }^{3}$ Department of Oceanography, University of Hawaii at Manoa, Honolulu, Hawaii, USA.

Corresponding author: J. Aucan, LEGOS, IRD, 14 Av. Edouard Belin, F-31400 Toulouse CEDEX, France. (jerome.aucan@ird.fr)

C2012. American Geophysical Union. All Rights Reserved. 0094-8276/12/2012GL052993
}

[Callaghan et al., 2006; Tait, 1972]. The number and severity of these wave-driven flooding events vary from year to year owing to changes in the regional wave climate.

[3] Previous studies and estimates of North Pacific storminess and wave climate variability have used wind or wave hindcast products [Graham and Diaz, 2001; Caires et al., 2004; Aucan, 2006], ship data [Gulev and Grigorieva, 2006], satellite data [Young et al., 2011], continental US tide gauge data [Bromirski et al., 2003], seismic data [Bromirski et al., 1999] or buoy data [Gemmrich et al., 2011]. Gulev and Grigorieva [2006] report an increase in winter significant wave height throughout the entire North Pacific, for both wind sea and swell wave heights. Bromirski et al. [2003] use records from the San Francisco tide gauge as an indicator of storm-forced water level changes in the Eastern North Pacific and find an increase in the severity of extreme events while mean storminess has not exhibited a significant trend. Graham and Diaz [2001] show an increase in storminess in the North Pacific Ocean (based on wind speeds and sea level pressure) and a correlation between storminess and climate indices such as the Pacific Decadal Oscillation (PDO) [Zhang et al., 1997]. Graham and Diaz [2001] also show a shift in the direction of extreme wind in the central North Pacific, including in the vicinity of Midway Atoll. In this study we focus on the response to wave forcing of the Midway Atoll in the Central North Pacific, as measured by an historical tide gauge located within the lagoon. We first show that waves are indeed the primary driver of winter sea level anomaly (SLA) within Midway Atoll. We then show that the seasonal (Dec-Jan-Feb) number of high SLA events correlates well with the mean seasonal wave height over a portion of the North Pacific and we argue that the seasonal number of high SLA events recorded at the Midway tide gauge can be used as a reliable proxy for storminess in the central North Pacific over the last 60 years. We use the homogeneous 60 year-long dataset of tide gauge water level at Midway, to show an increasing trend in the number of storm-driven swell events impacting Midway over the 1947-2010 period. In contrast, we find no trend in the amplitude of SLA events. After comparing our results to climate indices of the region (PDO, and North Pacific Index), we conclude that this observed increasing trend in the number of extreme events can be mostly attributed to low-frequency climate variability of the North Pacific.

\section{Methods and Study Site}

[4] Midway $\left(28^{\circ} 12 \mathrm{~N}, 177^{\circ} 21 \mathrm{~W}\right)$ is a subtropical coral atoll in the Northwestern Hawaiian Islands (Figure 1). Despite its location near the current northern limit of coral atoll formation [Grigg, 1982], it is of classic atoll morphology with a semi-circular reef crest emergent to $0.5 \mathrm{~m}$ depth 

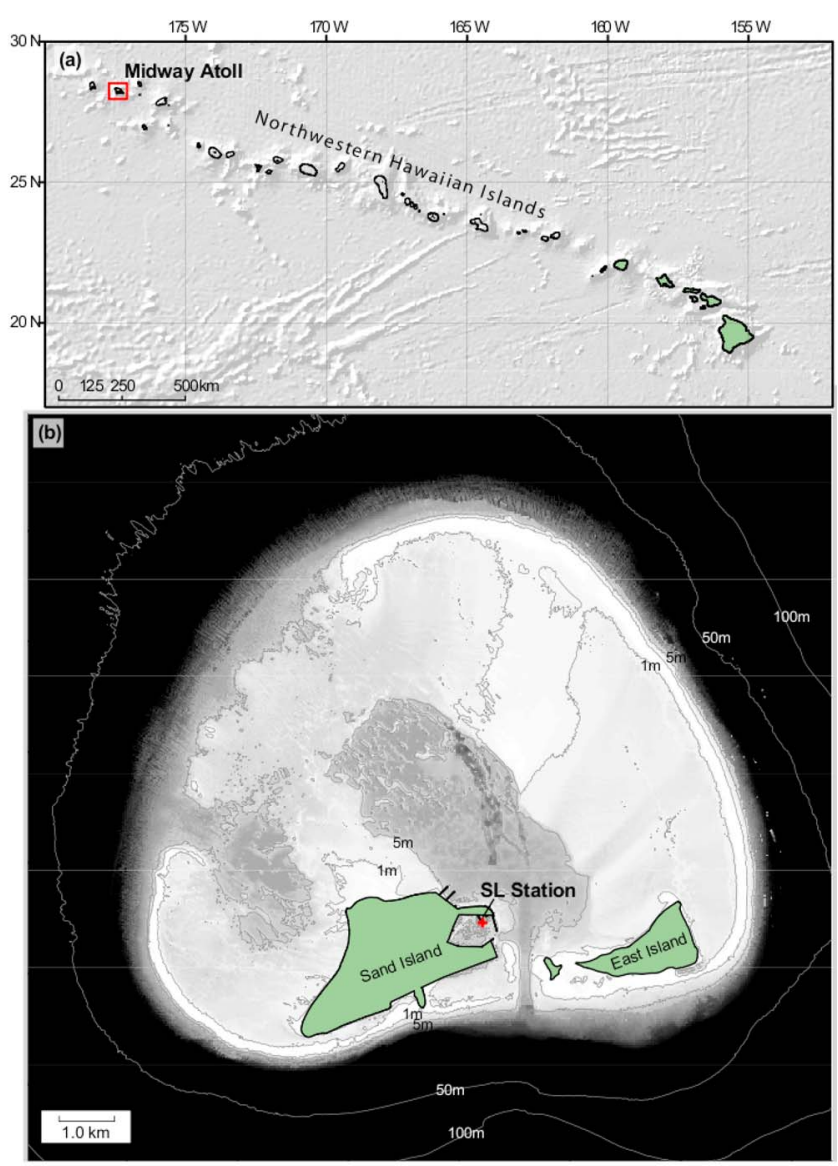

Figure 1. Location map of Midway Atoll. in most places, reef flats and a lagoon ranging from $1-12 \mathrm{~m}$ deep. Two small islands are located along the southern rim, with maximum elevations of about $2.5 \mathrm{~m}$. There is a single naturally occurring pass ( $\sim 1 \mathrm{~km}$ wide, $5 \mathrm{~m}$ deep) on the western side and a man-made channel dredged across the southern reef crest as the atoll was the site of a U.S. Navy base (the World War II "Battle of Midway" occurred here) for much of the 20th Century. The National Oceanic and Atmospheric Administration (NOAA) maintains a sea level station that provides the data this study is based on, which is located in the atoll lagoon on the northern shore of Sand Island (Figure 1).

[5] Tides in the area are of a mixed microtidal regime, with neap ranges of around $0.3 \mathrm{~m}$ and spring ranges around $0.6 \mathrm{~m}$. Trade winds are prevalent throughout the year (typically $5-10 \mathrm{~m} / \mathrm{s}$ from the east); however due to Midway's position towards the northern edge of the North Pacific trade wind belt, trade wind events are somewhat reduced in frequency and intensity compared to more southerly locations in the Hawaiian Islands. Trade wind wave conditions are typically $1-3 \mathrm{~m}$ in height with $8-11 \mathrm{~s}$ periods from the eastsoutheast. Average significant wave heights $\left(H_{s}\right)$ are $3-4 \mathrm{~m}$ in winter compared to less than $2 \mathrm{~m}$ in summer (Figure 2). Mean monthly maxima $H_{s}$ peak at 7-8 $\mathrm{m}$ in December and January (Figure $2 \mathrm{a}$ ). The large winter swells arrive primarily from the northwest with peak periods $\left(T_{p}\right)$ of $10-14 \mathrm{~s}$ and are associated with extratropical cyclones (Figure $2 b$ ).

\subsection{Datasets}

[6] We first use a combination of in-situ and remote data, as well as wave hindcast products to identify the causes of high SLA events at Midway over a period of $\sim 20$ years when all datasets overlap. The datasets we use are described in the auxiliary material and include in-situ sea level, sea surface height from altimetry, meteorological parameters
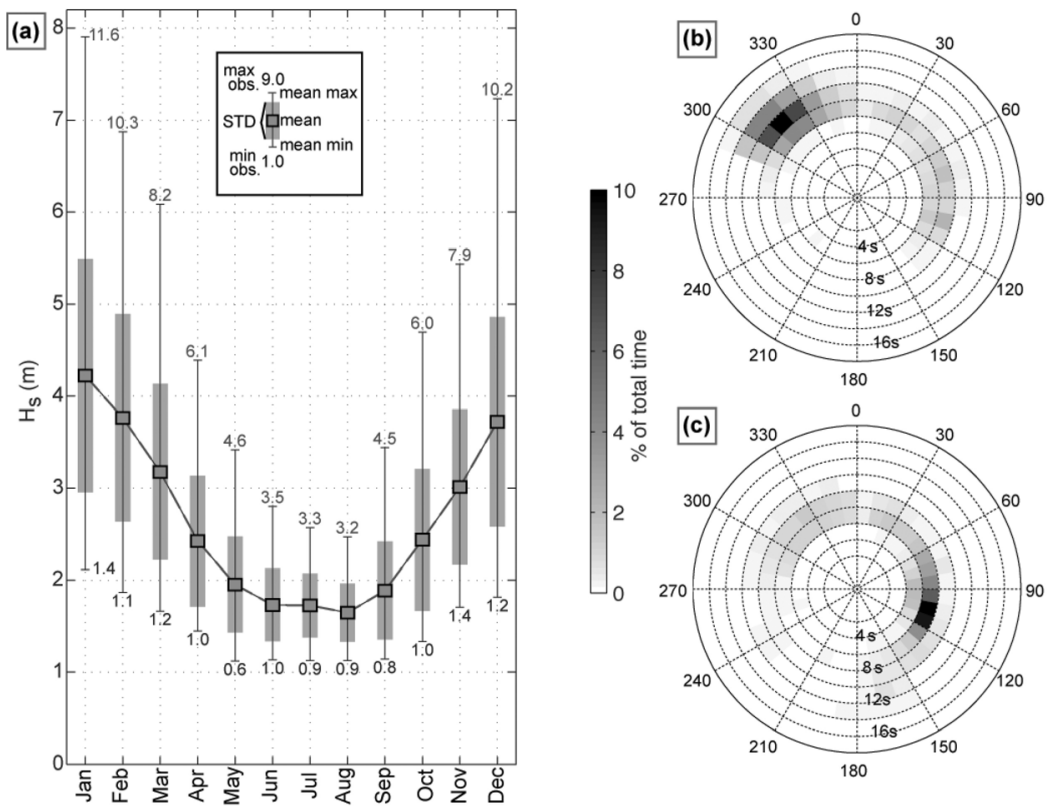

Figure 2. (a) Monthly wave climatology at Midway, and distribution of waves frequency-direction (b) for November through March and (c) from May to September. 

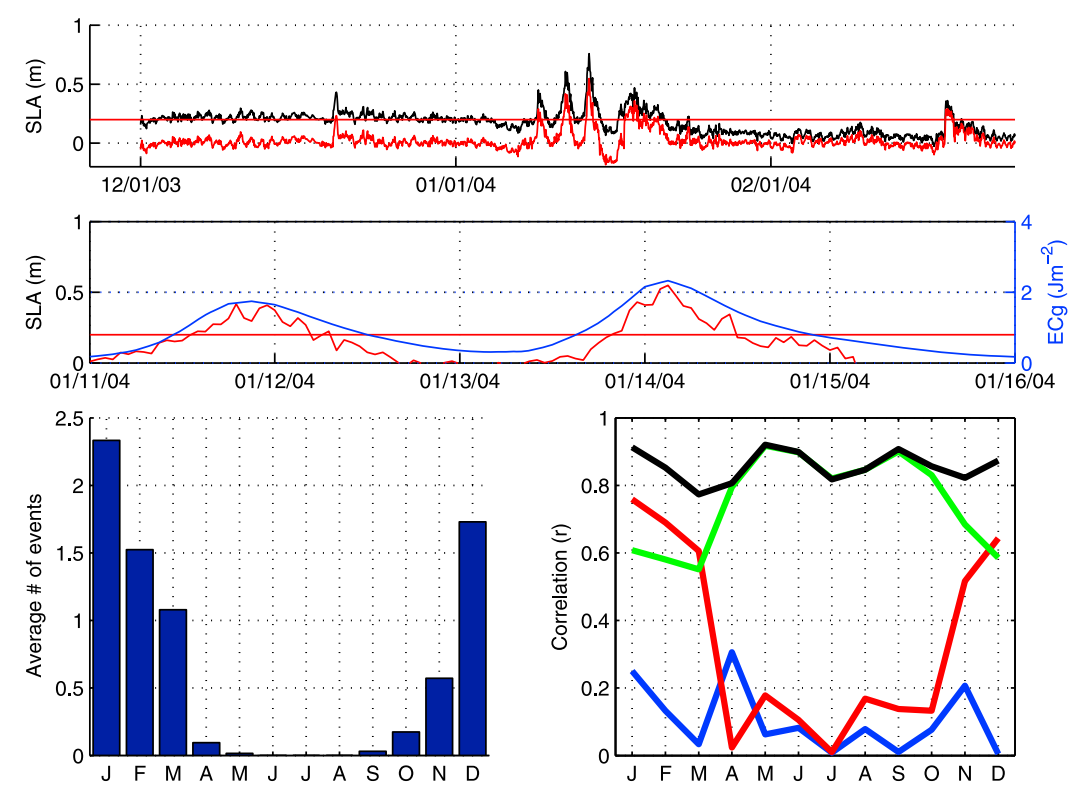

Figure 3. (top) Season-long snapshot of SLA time-series for December 2003-February 2004 (black line), The red curve is the high-passed SLA used to define extreme events. The horizontal red line indicates the $0.2 \mathrm{~m}$ threshold used in this study. (middle) Five-day-long snapshot of high-passed SLA (red) and wave energy flux (blue). (bottom left) Monthly distribution of the number of extreme SLA events (SLA $>0.2 \mathrm{~m}$ ). (bottom right) Average monthly correlation between observed SLA and modeled SLA based on a linear regression on wind (blue), waves (red) and SSH (green), and all three (black).

and wave parameters. ${ }^{1}$ After we show waves are the primary driver of these events, we use the SLA timeseries together with a longer wave reanalysis product ( $\sim 40$ years) to show the geographical extent of the correlation between the seasonal number of extreme SLA events and the winter mean seasonal wave height. Finally we use the tide gauge record alone ( $\sim 60$ years) to illustrate trends and variability of storminess in the central North Pacific.

\section{Results}

\subsection{Observed Sea Level Anomalies at Midway}

[7] Time series of SLA illustrate the short-term, positive amplitude events that are prevalent at Midway throughout the winter months (Figure 3, top). The events typically last 1-2 days, with amplitudes of $0.3 \mathrm{~m}$ on average, reaching a peak value of nearly $1 \mathrm{~m}$ (Figure 3 , top). We consider highpass filtered SLA anomalies that exceed $0.2 \mathrm{~m}$ as indicative of the positive amplitude events. SLA variance is nearly three times higher in January than in August (not shown).

[8] The relative contributions to SLA of waves, wind stress, and SSH are examined for each month of the year. The correlation of each variable separately with SLA differs over the course of the year (Figure 3, bottom right). SLA has a much higher correlation with waves in winter (when SLA variance is high) than during the summer. Conversely, the SLA signal is highly correlated with SSH in summer, when SLA variance is low. Wind stress generally is poorly correlated with SLA throughout the year. This leads us to conclude that the largest SLA events occurring in winter are primarily caused by high swell waves from distant storms.

${ }^{1}$ Auxiliary materials are available in the HTML. doi:10.1029/ 2012GL052993.
Comparison of Midway sea level with the WaveWatch III hindcast confirms that the energetic winter SLA events occur during high wave conditions. A 10-day comparison (Figure 3, middle) illustrates the close correspondence between the deep water wave energy flux and the highpassed SLA time series. The correlation between WaveWatch III wave energy flux and the SLA time series is 0.93 with a p-value of less than 0.01 .

[9] We then use the high-passed SLA to identify individual extreme events, which we define as an event that exceeds $0.2 \mathrm{~m}$, with individual events separated by at least 2 days. Expectedly, extreme SLA events occur nearly exclusively during winter months (Figure 3, bottom left), consistent with a similar seasonality of the wave climate (Figure 2). We note that our analyses of extreme SLA events are qualitatively similar using thresholds of 0.3 or $0.4 \mathrm{~m}$. The number of events and average amplitudes vary with threshold, but the seasonality and relative changes over time have a similar character.

[10] We examine year-to-year changes in SLA events during the winter months December through February. We did not include March in this analysis even though it is an active month for SLA events (Figure 3) because of a higher number of gaps in the Midway time series during March compared to December through February. The number of SLA events ranges from 2 to 16 (Figure 4a), with a noticeable increase after 1980. The average number of SLA events/year is 4.7 before 1980 compared to 7.7 after 1980 . The increase leads to a statistically significant increasing trend in the number of events (Figure 4a). The significance levels for the trends shown in Figure 4 are obtained using a Monte-Carlo simulation where extreme events were randomly reassigned to a different time over the 60 year record. For the $0.2 \mathrm{~m}$ threshold, the observed rate of increase 

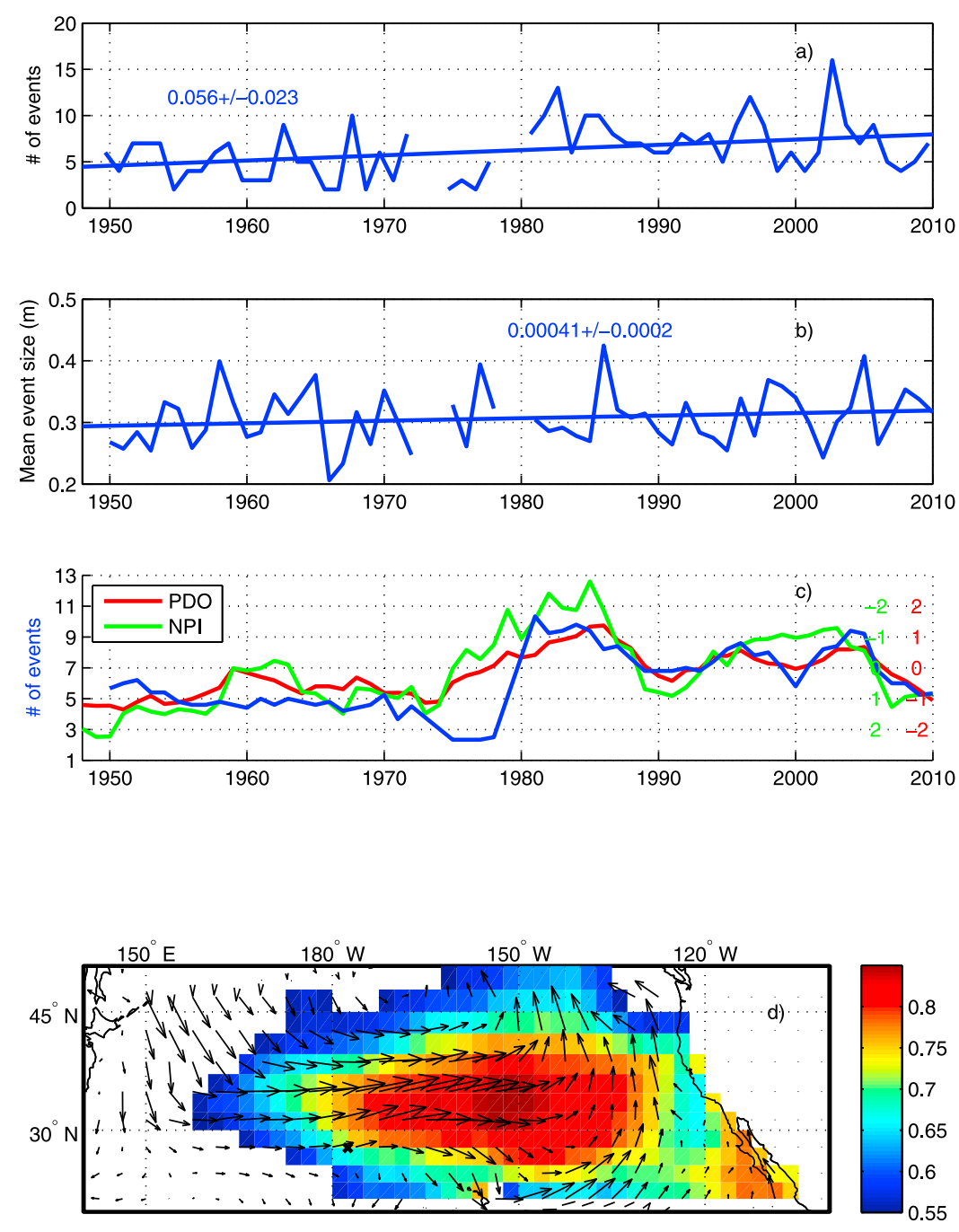

Figure 4. (a) Yearly repartition of the extreme SLA events larger than $0.2 \mathrm{~m}$. (b) Mean size of the extreme SLA events larger than $0.2 \mathrm{~m}$. (c) Number of extreme SLA events larger than $0.2 \mathrm{~m}$ (blue), PDO Index (red) and NPI (green) after a 5 years low-pass filter is applied. (d) Correlation maps between MSWH and observed number of seasonal SLA events at Midway (colors), and regression of the mean NCEP wind field on the PDO index (arrows).

( 0.056 event/yr) corresponds to 1 additional extreme event every season after 20 years (Figure 4a). However, this increasing trend appears to be associated with long term variations and the step-like increase between 1970 and 1980 .

[11] The seasonal mean amplitude of the SLA events varies from $0.2 \mathrm{~m}$ to just over $0.4 \mathrm{~m}$ with a mean value of $0.3 \mathrm{~m}$ (Figure $4 \mathrm{~b}$ ). The mean event size is not significantly correlated with the number of events. The event size also does not exhibit a noticeable offset after 1980 in contrast to the number of events, and the linear trend in event size is positive and significant, but weak (Figure 4b).

\subsection{Historical North Pacific Storminess and Wave Climate}

[12] In this section we investigate the temporal variability of our observations at Midway Atoll and the relevance of our observations at one point in the North Pacific for the study of basin scale variability. Wave climatology in the Pacific is related to large scale climate indices [e.g., Graham and Diaz, 2001; Bromirski et al., 2003; Aucan, 2006], notably the PDO and the North Pacific Index (NPI) [Trenberth and Hurrell, 1994].

[13] The correlation between the observed number of extreme SLA events per season (Dec-Feb) and the PDO Index and the NPI, after a 5-year running mean filter is applied, is 0.70 and -0.58 respectively (Figure $4 c$ ). Over decadal time scales, the number of extreme SLA events appears to increase between 1970 and 1980 (Figure 4c), similar to a shift from the cold to the warm PDO phase around the same time. If we fit and remove the PDI index from the observed number of events, the residual does not exhibit a significant linear trend, suggesting that the observed increase in events is associated with multidecadal climate variability and not a secular trend. The mean event size is not significantly correlated with the PDO. This is consistent with results from Graham and Diaz [2001] who found an increase in extreme wind speeds northwest of Midway, but a shift in extreme wind direction away from the atoll. As a result, the extreme wind component (and the associated wave height) directed towards Midway Atoll experiences little or no trend. 
[14] To investigate the geographical extent of the inferred wave signal at Midway, we use the ECMWF-ERA40 reanalysis which covers the 1957-2001 period. We calculate correlations between mean seasonal (Dec-Jan-Feb) wave height (MSWH) from the model versus the number of extreme SLA events during the same winter period at Midway. We use the number of events rather than the amplitude of the events because we do not have the ability to invert SLA amplitude within the atoll into offshore wave height. The MSWH and the number of extreme SLA events per season were filtered with a 5-year running mean filter before correlations were calculated. Correlations $(c)$ exceed 0.85 near Midway, and are statistically significant $(c>0.55)$ over a wide area of the central North Pacific (Figure 4d). Therefore, the seasonal number of extreme SLA events at Midway is not only representative of the seasonal wave climate at Midway, but also representative of the seasonal wave climate of a sizeable portion of the North Pacific Ocean. As a result, we argue that the statistics of extreme SLA events measured at Midway can be used as a proxy for central North Pacific storminess. Additionally, the area of highest correlation between MSWH and number of extreme events at Midway compares well geographically with the averaged wind field fluctuations associated with the PDO (Figure 4d), consistent with our observation that the number of extreme events at Midway correlates with the PDO index.

\section{Discussion}

[15] We note that while we show an increase in the number of extreme wave-driven SLA events per season, the mean size of these extreme SLA events does not show any notable trend (Figure 4). The latter is in contrast with previous studies which show an increase in the severity of extreme wave/wind events [Graham and Diaz, 2001; Bromirski et al., 2003]. We have also shown that the number of these extreme SLA events per season correlates well with the mean seasonal wave height (MSWH)in the Central North Pacific around Midway (Figure 4d), and that this MSWH (from the ERA40 reanalysis) in the Central North Pacific also increases (not shown). We therefore suggest that the increase in MSWH in the Central North Pacific could be due to an increasing number of storms each season, as opposed to an increase in storms severity. We note however that a change in average storm tracks in the North Pacific could also affect the number of events recorded at one point (in our case Midway Atoll) with other parameters remaining equal (number and severity of storms). Unfortunately, no homogeneous wave height dataset is available over the full timeperiod when we have in situ sea level data at Midway (1947-2010) and an in-depth study of storm tracks from wave model reanalyses over the past 60 years is beyond the scope of this paper.

\section{Conclusions}

[16] Waves impacting the reef surrounding Midway Atoll are the primary driver of SLA measured at a tide gauge within the lagoon. Given the location of the tide gauge, the inundation is likely atoll-wide and inundation levels of $\sim 1 \mathrm{~m}$ have been measured. This result further highlights that wave-driven SLA events with the potential for island inundation may occur at oceanic coral atolls when the nearest storm is hundreds to thousands of kilometers distant. Inundation of low-lying islands, at times with severe consequences, has previously been documented throughout the Pacific and Indian Oceans when distant source, long-period ocean swells coincide with local astronomical high tides [Caldwell et al., 2009; Hoeke, 2009]. However, all tide gauges do not react similarly to offshore wave forcings [Merrifield et al., 2007], so the methods used in this paper may not be readily applicable for other tide gauge data. Trends in North Pacific storminess have already been studied with a number of different datasets such as offshore wave buoys, ship observations, satellite data and wind or wave re-analysis. Each of these datasets was found to have caveats such as steplike offsets in buoy records due to changes in hardware or processing [Gemmrich et al., 2011], relatively short record length for satellite data, inaccuracies in visual observations from ships and uncertainties of wind products for wind and wave models prior to the satellite era. Despite these caveats, most studies show an increase in storminess in the North Pacific over the last few decades.

[17] In this paper, after showing that extreme SLA events are caused by waves at the Midway tide gauge, we show that the time series of the seasonal number of high SLA events can be used to evaluate storminess in the Central North Pacific. Based on the tide gauge data, we independently show an increasing trend in North Pacific storminess, confirming the results of earlier studies that used completely different and independent datasets. This increase in storminess appears to be due to an increase in the number of storms per season, rather than an increase in individual storm intensities, although a change in storm tracks cannot be conclusively ruled out. The increase in the number of extreme SLA events at Midway and the corresponding increase in storminess in the Central North Pacific, as well as their low frequency variability, are attributed to climatic variations in the central North Pacific wind field, as captured by the PDO index and to a lesser extend the NPI.

[18] Acknowledgments. The authors are grateful to Johannes Gemmrich and an anonymous reviewer for comments that greatly improved this manuscript. Author JA worked on this manuscript during two visits to UHLSC, that were funded by an internal LEGOS grant, and by a TOSCA/ CNES grant. Author JA is grateful to Doug Luther, SOEST, for providing adequate work space during these visits. Author RKH was supported during part of this work by NOAA's Coral Reef Conservation Program.

[19]. The Editor thanks Johannes Gemmrich and an anonymous reviewer for assisting in the evaluation of this paper.

\section{References}

Andrefouet, S., J. Pages, and B. Tartinville (2001), Water renewal time for classification of atoll lagoons in the Tuamotu Archipelago (French Polynesia), Coral Reefs, 20, 399-408.

Aucan, J. (2006), Directional wave climatology for the Hawaiian Islands from buoy data and the influence of ENSO on extreme wave events from model hindcast, JCOMM Tech. Rep. 34/WMO-TD 1368, World Meteorol. Organ., Geneva, Switzerland.

Bromirski, P. D., R. E. Flick, and N. Graham (1999), Ocean wave height determined from inland seismometer data: Implications for investigating wave climate changes in the NE Pacific, J. Geophys. Res., 104(C9), 20,753-20,766.

Bromirski, P. D., R. E. Flick, and D. R. Cayan (2003), Storminess variability along the California coast: 1858-2000, J. Clim., 16, 982-993.

Caires, S., A. Sterl, J. R. Bidlot, N. Graham, and V. Swail (2004), Intercomparison of different wind-Wave reanalyses, J. Clim., 17(10), 1893-1913.

Caldwell, P. C., S. Vitousek, and J. P. Aucan (2009), Frequency and duration of coinciding high surf and tides along the north shore of Oahu, Hawaii, 1981-2007, J. Coastal Res., 25(3), 734-743. 
Callaghan, D. P., P. Nielsen, N. Cartwright, M. R. Gourlay, and T. E. Baldock (2006), Atoll lagoon flushing forced by waves, Coastal Eng., 53(8), 691-704

Gemmrich, J., B. Thomas, and R. Bouchard (2011), Observational changes and trends in northeast Pacific wave records, Geophys. Res. Lett., 38 , L22601, doi:10.1029/2011GL049518.

Graham, N., and H. Diaz (2001), Evidence for intensification of North Pacific winter cyclones since 1948, Bull. Am. Meteorol. Soc., 82(9), 1869-1886.

Grigg, R. W. (1982), Darwin Point: A threshold for atoll formation, Coral Reefs, 1, 29-34

Gulev, S. K., and V. Grigorieva (2006), Variability of the winter wind waves and swell in the North Atlantic and North Pacific as revealed by the voluntary observing ship data, J. Clim., 19(21), 5667-5685.

Hoeke, R. (2009), NOAA Ship Hi'ialakai, Cruise Rep. CRHI0901, NOAA, Honolulu, Hawai'i.

Longuet-Higgins, M., and R. Stewart (1964), Radiation stresses in water waves; a physical discussion, with applications, Deep Sea Res., 11, 529-562.
Merrifield, M. A., Y. L. Firing, and J. J. Marra (2007), Annual climatologies of extreme water levels, in Extreme Events: Proceedings Aha Hulikoá Hawaiian Winter Workshop, pp. 27-32, Sch. of Ocean and Earth Sci. and Technol., Honolulu, Hawaii.

Munk, W., and M. Sargent (1948), Adjustment of Bikini Atoll to waves, Trans. Am. Geophys. Union, 29(6), 855-860.

Symonds, G., K. P. Black, and I. R. Young (1995), Wave-driven flow over shallow reefs, J. Geophys. Res., 100, 2639-2648.

Tait, R. J. (1972), Wave set-up on coral reefs, J. Geophys. Res., 77(12), 2207-2211.

Trenberth, K. E., and J. W. Hurrell (1994), Decadal atmosphere-ocean variations in the Pacific, Clim. Dyn., 9, 303-319.

Young, I. R., S. Zieger, and A. V. Babanin (2011), Global trends in wind speed and wave height, Science, 332, 451-455.

Zhang, Y., J. Wallace, and D. Battisti (1997), ENSO-like interdecadal variability: 1900-93, J. Clim., 10, 10,004-10,020. 